\title{
FRAGMENTOS DE UN DISCURSO JURÍDICO: LA DESCONTEXTUALIZACIÓN DEL LÉXICO JUDICIAL Y SU EFICACIA CÓMICA EN COMENSALES DE ARISTÓFANES*
}

\author{
EMILIANO JERÓNIMO BuIS \\ Universidad de Buenos Aires \\ ejbuis@yahoo.com

\begin{abstract}
FRAGMENTS OF A LEGAL DISCOURSE: THE DE-CONTEXTUALIZATION OF LEGAL VOCABULARY AND ITS COMIC EFFECTIVENESS IN ARISTOPHANES' BANQUETERS
\end{abstract}

Para Elena F. Huber (†), maestra incansable, sin cuya pasión por el mundo griego y su carisma único para transmitirlo nada de esto habría sido posible.

La presencia de una terminología jurídica es permanente en los fragmentos trasmitidos de la primera comedia aristófanica, $\Delta \alpha \iota \tau \alpha \lambda \tilde{\eta} \varsigma$ 'Comensales'. A partir de un estudio filológico de los pasajes, nuestro propósito consiste en mostrar cómo, frente a un público conocedor de los trasfondos de la justicia,
The presence of legal vocabulary is permanent throughout the fragments which have survived from Aristophanes' first comedy, $\Delta \alpha \imath \tau \alpha \lambda \tilde{\eta} \varsigma$ 'Banqueters'. By means of a philological study of those verses, the purpose of this article is to show how the sophistic handling of the technical terms of tribunals

* Una versión anterior de este artículo, mucho menos desarrollada, fue leída como ponencia en el marco del XVIII Simposio Nacional de Estudios Clásicos «Creencias y Rituales en el Mundo Clásico», organizado por la AADEC, la Facultad de Humanidades de la Universidad Nacional de Mar del Plata y la Facultad de Humanidades de la Universidad del Comahue, y que tuvo lugar en Mar del Plata, Argentina, del 3 al 6 de noviembre de 2004. Este estudio forma parte de los trabajos llevados a cabo en el marco del Proyecto de Investigación I+D+I (2008-2011) «Familia y propiedad en el derecho griego antiguo» (FFI2008-00326/FILO), dirigido por la Prof. ${ }^{a}$ Dra. Inés Calero Secall, de la Universidad de Málaga, aprobado por la Dirección General de Investigación del Ministerio de Ciencia y Tecnología de España, y del Proyecto F459 «Género, familia y legalidad en la literatura griega antigua: manifestaciones textuales de los vínculos jurídico-institucionales del matrimonio y el parentesco» (UBACyT 2008-2010), dirigido por la Prof. ${ }^{a}$ Dra. Elsa Rodríguez Cidre y co-dirigido por mí en la Universidad de Buenos Aires. 
tanto la manipulación sofística del léxico técnico de los tribunales cuanto el quebrantamiento de sus condiciones solemnes de aplicabilidad se transforman en un eficiente mecanismo de comicidad.

Palabras clave: Comensales; Aristófanes; recursos cómicos; derecho ateniense; vocabulario técnico. and the breakdown of their formal conditions of application become an effective comic mechanism before an audience who is used to understanding the backgrounds of justice.

Keywords: Banqueters, Aristophanes; comic devices; Athenian law; technical vocabulary.

\section{Nuestro propósito}

El derecho ático se caracterizó siempre por una suerte de amateurismo de base. En efecto, hoy parece constituir una práctica recurrente entre los especialistas la demostración del hecho de que la inexistencia de abogados o de juristas especializados, así como la falta de profesionalización de la labor de los jueces, investía al sistema jurídico de Atenas de un delicado tinte popular que lo apartó de un elitismo intelectual. Desde una lectura comparativa, parece evidente ya que, lejos de la oratoria aristocrática romana, los atenienses del periodo clásico consideraban la praxis retórica de las cortes como un ejercicio cívico más dentro de las múltiples actividades políticas que permitía $-\mathrm{y}$ a las que instaba - el régimen democrático.

Sin embargo, es preciso considerar simultáneamente que esta aparente «popularización» del saber jurídico presuponía una contrapartida necesaria: todos los atenienses varones y mayores de edad formaron parte, al menos en alguna ocasión, de alguno de los extensos paneles de magistrados que decidían con sus votos las controversias judiciales. La falta de experticia en la tramitación de las causas contenciosas y la aparente democratización del ejercicio forense no implicó, empero, la ausencia de un léxico propio en el seno de los juicios, que los logógrafos y clientes empezaron rápidamente a reproducir para conseguir triunfos rotundos mediante el convencimiento retórico de los jurados. Enseguida hizo su aparición una suerte de vocabulario semi-técnico de derecho, fundado en los términos habituales del griego ático pero recubierto de una significación progresivamente más acotada y menos laxa en el espacio tribunalicio, que pasó a ser usado en dichos alcances casi con exclusividad en conexión con los procedimientos legales ${ }^{1}$. De ese modo, si bien el criterio de la inteligibilidad seguía siendo importante, la conside-

1 Frente a una afirmación extrema como la de Carey 1994, p. 178 («... there is a marked absence of specifically legal terminology»), somos partidarios de una visión más realista y 
rable experiencia popular en la labor de los juicios y la solemnidad de la que solían estar revestidos los actos en todo el mundo mediterráneo clásico explican bien la paulatina existencia de un reconocimiento generalizado de ciertas expresiones «jurídicas»y, sobre ese telón de fondo, la conformación con el tiempo de un número de expertos más familiarizados con la jerga de las cortes.

En la obra $\Delta \alpha \imath \tau \alpha \lambda \tilde{\eta} \varsigma$ 'Comensales', que data de una época en que - según se nos dice- Aristófanes todavía era muy joven para instruir $\operatorname{coros}^{2}$ (427 a. C.), un discurso que nos llega de modo fragmentario reproduce testimonios aislados que señalan el germen de una temática que será recurrente en su escritura: la contraposición conocimiento/ignorancia respecto del saber legal. El presente trabajo propone analizar - mediante un método filológico - algunos pasajes correspondientes a la pieza, para advertir el espacio dialéctico establecido entre uno de los personajes cómicos, que esboza su argumentación mediante lexemas técnicos propios de la práctica sofística de la abogacía, y sus parientes desconocedores de los artilugios tribunalicios. Desde estos versos, se procura plantear una clara distinción textual entre aquellos que manejan la retórica específica de un vocabulario ritualizado propio de la corte y quienes — legos en la materia - ignoran su sentido ${ }^{3}$.

sostenemos junto con Todd 1993, p. 61, n. 14, que «... Athens never developed a technical but at most only a semi-technical vocabulary».

2 Esto, evidentemente, es un punto discutido. Se ignora si la limitación etaria procedía de una prohibición legal o de constricciones impuestas por patrones de comportamiento sociales. El testimonio de $N u$. 530, que indica en una primera persona que el autor era una «doncella» todavía en aquellos tiempos y por lo tanto no estaba en condiciones de dar a luz

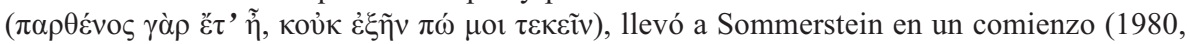
p. 24, n. 2) a considerar que «in 427 Aristophanes would have been regarded as too young to come forward in person as a comic didaskalos». En su edición de Nubes, sin embargo, matizó su posición al afirmar que este pasaje, en realidad, «does not prove that in $427 \mathrm{Ar}$. was legally debarred by reason of age from acting officially as a producer (didaskalos) at a major dramatic festival; at most it implies that many people would have thought it improper or presumptuous for a young man to do so» (1982, pp. 187-188, ad loc.). Tal vez esta última interpretación, más moderada, constituya actualmente la posición mayoritaria entre los críticos.

3 Algunos trabajos recientes exploran la importancia de los registros técnicos en la comedia aristofánica, tales como Kloss 2001, Willi 2003, López Eire 2003 o Beta 2004. 


\section{El teatro y la justicia como espectáculos ritualizados}

La asamblea, el drama y las cortes constituían en la Atenas clásica espacios privilegiados para la puesta en acto de discursos públicos; la consagración de instancias abiertas de participación ciudadana estaba, en esencia, inescindiblemente vinculada con el poder de la actividad política. Como ya hemos tenido ocasión de demostrar en un trabajo previo (Buis 2004a), las semejanzas entre el teatro y el ejercicio judicial son, en efecto, indudables ${ }^{4}$. En tanto objeto de performance o representación social ${ }^{5}$, todo texto dramático o argumento legal era compuesto para ser llevado desde la escritura hasta la puesta en escena, donde los efectos comunicativos del discurso se cruzaban con una semántica visual ${ }^{6}$. Numerosas coordenadas e indicaciones físicas en la arquitectura de estos lugares constituían pautas evidentes de identificación de participantes, jueces y asistentes, y la distribución espacial contribuía a definir los roles: acusadores y querellados, actores y coreutas ocupaban su sitial determinado para ser escuchados y vistos ${ }^{7}$ por un gran número de oyentes/espectadores ${ }^{8}$ que se involucraban, más o menos (inter)activamente, con el relato oral.

Prefijados en el seno de un debate agónico siempre reglado9, los litigantes y los actores representaban sus papeles, en una dimensión comunitaria que im-

4 «... these legal and dramatic verbal contests shared various details of procedure and administration which suggested their equivalence to democratic audiences. Some of the resemblances were elaborately specific» (Garner 1987, p. 97). Véase también Ober y Strauss 1990, Hall 1995; Wiles 2000, p. 131, y Todd 2005, para citar solamente los trabajos más representativos.

${ }^{5}$ Sobre la importancia de la noción de performance para el contexto democrático, v. Goldhill 1999, p. 1. Acerca de un rastreo bibliográfico diacrónico - y sus principales avances - sobre la performance aplicada a los estudios sobre teatro en el mundo griego, v. más recientemente Revermann 2006, pp. 9-13.

${ }_{6}$ Kavoulaki 1999, p. 294, sostiene que «... processional ritual shares with theatrical performances — performances par excellence - an explicitly declared emphasis on viewing».

${ }^{7}$ Green y Handley 1995, pp. 11-13. La voz era un factor esencial del espectáculo: «A performer, whether actor or orator, with an outstanding, professionally trained voice could give intense pleasure to large audiences in open-air theatres and places of assembly...» (Easterling 1999, p. 160).

8 Wallace 1997 habla de una verdadera «theatrocracy» en Atenas, para dar cuenta de la importancia cultural del público en las actividades performativas de la pólis.

9 Como sostiene Wiles 2000, p. 57, «Plaintiff and defendant, standing on two platforms facing the audience, were engaged in a process of self-dramatization». 
plicaba una manifestación de la autoridad política del $\delta \tilde{\eta} \mu o \varsigma^{10}$. En este sentido, tanto el teatro como el foro constituían medios de representación de valores colectivos y simbólicos en una esfera pública ${ }^{11}$. Una serie de elementos convencionales compartidos, incluso con variantes más o menos flexibles ${ }^{12}$, los transformaba en ceremonias formales profundamente estructuradas, que en un punto permanecen cercanas a sus orígenes como actos religiosos. La puesta en escena teatral implica, entonces, un punto de contacto donde los orígenes sagrados se embeben, en el propio ejercicio de la performance, de una significación cívico-social que lo tornan un ejemplo claro de ritual político ${ }^{13}$.

En otras palabras, podemos afirmar que, en su naturaleza compleja, el procedimiento judicial y el espectáculo dramático — en tanto pretendían consolidar un orden conservador y reproducir el esquema tradicional de poder y la ideología oficial - eran entonces una suerte de instancias de ritualismo secularizado o, mejor aun, verdaderas experiencias de performance social ${ }^{14}$, dado que constituyen un complejo codificado de conductas sistemáticas y repetitivas. Las reglas estereotipadas que lo constituyen crean y promueven valores fundamentales dentro de una sociedad, a través de la representación y la construcción de una realidad ${ }^{15}$.

En estas ceremonias, todo ocupaba su lugar tradicional en el marco de un escenario de solemnidad; los actores y oradores debían ensayar y memorizar

10 Ambas instituciones, las cortes y el teatro, constituían medios para ganar estatus y autoridad dentro del plano político de la ciudad, y entonces estas performances se convirtieron en instrumentos claves del poder.

11 Soulier 1991, p. 17.

12 Nos hacemos eco aquí del comentario de Goldhill 1989, pp. 179-180, cuando, frente a la postura más radical de Wiles 1987, aclara que «conventions in theatre are constructed in more or less rigour but always as a "range of possibilities"».

13 Revermann 2006, p. 31: «Greek theatre performances, then, are ritualistic performances, to such an extent that ... they are best conceptualized as a triad of social drama/theatre/ ritual, with theatre as the dominant».

14 «Politics, then, meshed the political organs, especially the Assembly and the law-courts together. So too did performance, for just as the courts could be a political arena, so the Assembly was a place where performance mattered as in the law courts and theatre» (Worthington 2004, p. 130).

15 «Ritual both "represents" and at the same time "constructs" an ideal reality, transforming perception and sustaining belief in that reality ... The appeal of ritual may be in its power to make the group visible and intelligible to itself, not of course completely so, but rather by constructing a single determinate social reality from out of the chaos of all possible forms»» (Seaford 1994, p. xii). 
sus discursos para luego fingir que improvisaban en un contexto donde en verdad nada parecía ser dejado al azar. La asamblea, los tribunales y el teatro representan así, básicamente, un reservorio de actividades performativas por excelencia y, en este sentido, exigían de quienes participan de ellos la utilización de un vocabulario específico y formalmente condicionado.

Ambas instancias democráticas se cruzan de modo evidente sobre el escenario de la comedia antigua. A pesar de la escasez de trabajos que consideran la comedia como fuente del derecho ático ${ }^{16}$, vemos que, ya desde las primeras líneas preservadas de su corpus literario, Aristófanes se nos presenta como un verdadero «experto» en el manejo de una terminología directamente vinculada con el derecho y con la educación en el ámbito de la justicia.

\section{Sofistica y derecho en Comensales}

Hay testimonios antiguos de que Aristófanes obtuvo el segundo premio ${ }^{17}$ por su comedia $\Delta \alpha \imath \tau \alpha \lambda \tilde{\eta} \varsigma$, representada durante el arcontado de Diotimo ${ }^{18}$. No hay ninguna fuente histórica que permita discernir, sin embargo, en el marco de qué festival dramático se presentó a concurso la obra: a pesar de ello, los autores se han encargado de inferir, con argumentos diversos, que se trataba de las Leneas ${ }^{19}$, o bien han tomado por un hecho que se trató de una repre-

${ }^{16}$ Con la comprensible excepción de algunos artículos específicos sobre Avispas, a mi entender solamente Carey 2000 ha brindado recientemente una visión de conjunto sobre la importancia del vocabulario jurídico en el corpus aristofánico. El interesante capítulo de Wallace 2005 en el Cambridge Companion to Ancient Greek Law sólo se focaliza en los asuntos legales que surgen de la libertad de expresión cómica y no avanza en el estudio del léxico forense. El último volumen publicado sobre las relaciones entre teatro y drama en el mundo grecorromano (Cantarella y Gagliardi 2007) tampoco contiene, a pesar del título, trabajos que se dediquen a la comedia antigua. Acerca de las alusiones legales y extrajudiciales en la comedia nueva - una temática que ha merecido mucho mayor interés entre los especialistas-, v. Scafuro 1997.

17 En la vieja edición de los escolios de Dübner 1855 el texto de $\Sigma$ RVAld ad Ar. Nub. 529

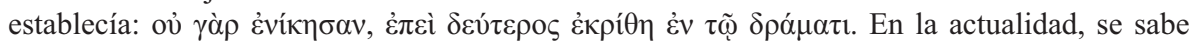
bien que el corpus de escolios antiguos de la edición Aldina fue tomado del manuscrito E, el que tenía en su poder el editor. Es preciso destacar, no obstante, que en la edición más reciente de los scholia aristofánicos (Holwerda 1977), la declaración de que Comensales obtuvo el segundo premio está presente en REMNp, pero no en V, tal como confirman bien Kassel y Austin 1984, p. 123, test. vi).

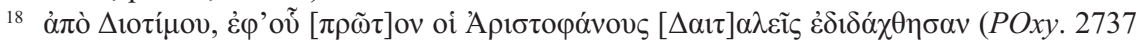
fr. 1 col. $1.3 \mathrm{~s}$.).

19 Cassio 1977, p. 20, siguiendo a Fritzsche 1831, p. 8. 
sentación ofrecida durante las Grandes Dionisias ${ }^{20}$. Una problemática propia de la comedia antigua, precisamente, se vincula con la coparticipación en la puesta teatral aristofánica de autor y productor ${ }^{21}$ : así, contamos con evidencia que nos indica que Aristófanes, por cuestiones de edad, tuvo que representar sus primeras obras amparado en el nombre de algún productor, sea Calístrato o Filónides ${ }^{22}$.

A pesar de que sólo conservamos un total de cincuenta y cuatro fragmentos (la gran mayoría de tan sólo un verso) ${ }^{23}$, la obra ha suscitado un interés desde antiguo ${ }^{24}$. En lo que hace a las temáticas que pueden advertirse en una primera lectura, no caben dudas de que la pieza gira en torno a la conflictiva relación entre padres e hijos, que, a la luz de las comedias conservadas, cabría concebir como un tema recurrente sobre el escenario ${ }^{25}$. Así, frente a un coro

20 Russo 1994, p. 13, habla de su «unofficial début» en las Grandes Dionisias; para sostener esto se basa en el escolio a $N u$. 529, donde se hace mención de que la referencia a los «virtuosos e invertidos» apunta a Comensales. Volveremos sobre este pasaje más adelante.

${ }^{21} \ll \ldots$ Aristophanes himself preferred to write the book and leave the producing/directing to someone else» (Silk 2000, p. 5).

22 Ar., Nu. 528-536. Fundado en un escolio al v. 531 (cf. Holwerda 1977), Welsh 1983 ha llegado a la conclusión de que fue Filónides el $\delta 1 \delta \alpha ́ \sigma \kappa \alpha \lambda o \varsigma$ de Comensales, interpretación seguida con argumentos propios por Gil 1989, pp. 74-75. En todo caso, es interesante el caso de Acarnienses, donde aparece una primera persona que puede referirse tanto al autor como a otro. Así, Van Leeuwen 1901, p. 67, sostenía que fue Calístrato y no Aristófanes quien debió soportar las calumnias de Cleón. Cf. Demont 1997, p. 473: «Ce n’est pas seulement Dicéopolis qui parle ... mais aussi Callistratos, le didascalos: bien sûr, tous les spectateurs avertis pensaient nécessairement aussi, et même principalement, à l'auteur Aristophane, qui avait probablement été nommément accusé peut-être en même temps que Callistratos, son prête-nom». Frente a estas posibilidades, creemos que, de acuerdo con las otras referencias personales del pasaje, el lexema $\delta i \delta \alpha ́ \sigma \kappa \alpha \lambda o \varsigma$ en el v. 628 de la comedia apunta por cierto a Aristófanes, y no a Calístrato. Sin embargo, tomado en un sentido aislado, reconocemos que el pasaje en sí no parece ser claro y podría estar indicando que la acción de Cleón se presentó contra uno, otro o ambos, y no necesariamente contra Aristófanes. Esta cuestión ha sido debatida por Brockmann 2003, p. 215 ss., y por Sommerstein 2004, pp. 159-160, n. 38. En el caso de Comensales tampoco sabemos muy bien si el público reconocía la autoría aristofánica, ya que ignoramos — como señala Sommerstein 1992, p. 32, n. 1- el grado de conocimiento que tenía el público acerca del escritor.

${ }^{23}$ En efecto, alrededor de un $40 \%$ de los pasajes preservados contienen menos de un verso, $35 \%$ son de exactamente un verso y sólo el $25 \%$ restante abarca más de un verso.

${ }^{24}$ Baste mencionar, en el siglo XIX, los comentarios monográficos de Fritzsche 1831 y Fåhraeus 1886, así como la tesis doctoral de Roeter 1888.

${ }_{25}$ La relación padre/hijo es un motivo privilegiado de la comedia antigua (cf. Strauss 1993; Sherberg 1995, p. 13). Sobre la temática de la filiación en Aristófanes, v. Bryant 1907. 
posiblemente compuesto por estos «comensales» a los que se refiere el título -que aludía a los participantes de algún banquete o ritual sagrado en honor a Heracles, aunque esto es una mera hipótesis $-{ }^{26}$, vemos que los personajes centrales son un padre con dos hijos varones ( $\mu \varepsilon \iota \rho \alpha ́ \kappa ı \alpha)$ muy diferentes entre sí. Por un lado, aparece el joven criado en el campo junto al anciano (al que

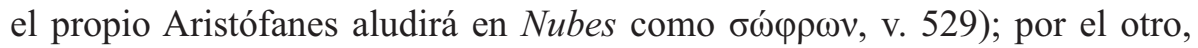
el muchacho educado en el ǒ́ $\tau$, a quien Aristófanes concebirá allí también

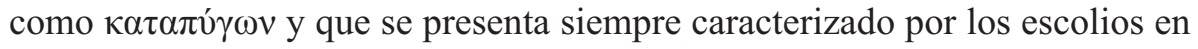
términos negativos.

Si bien no podemos reponer en todos los casos la atribución de líneas a cada uno de los actores, cuando el texto es más extenso - como es el caso del fragmento que la mayoría de los editores utiliza para encabezar los otros pasajes-, la tarea no parece ser tan complicada:

$$
\text { Fr. } 1 \text { (198 K, } 205 \text { K-A })^{27}
$$

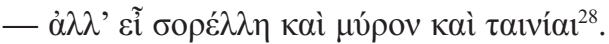

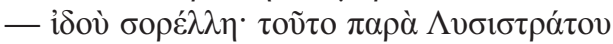

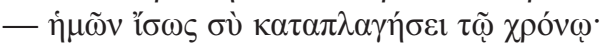

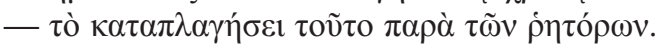

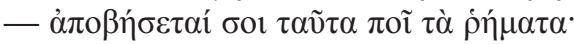

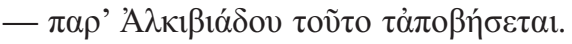

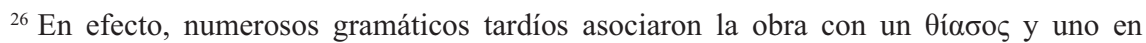
particular, Orión - junto con varias entradas léxicas derivadas de él— vinculó la pieza con

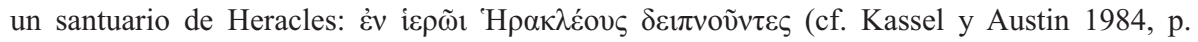
122). Para Foucart 1873 , p. 181, n. 4, por ejemplo, la palabra $\delta \alpha \iota \alpha \lambda \tilde{\eta} \varsigma$ se refiere a quienes integraban una comunidad religiosa. Lind 1985 ha recolectado pasajes de la comedia temprana de Aristófanes para concluir que el propio autor debió de haber frecuentado uno de estos tíaбot en su demo de origen. Para ello, se basa en parte en las conclusiones de Dow 1969, quien había identificado en una inscripción ateniense $\left(I G I^{2} 2324\right)$ varios nombres de individuos —nombrados en la comedia aristofánica - entre los $\theta 1 \alpha \sigma \tilde{\tau} \tau \alpha$ de un culto de Heracles. Según Gil 1989, p. 74, «es harto probable que el joven Aristófanes formara con los miembros de un thíasos de Heracles, integrado en su mayoría por paisanos suyos, el coro de los Daitalês, transformando la cofradía real en un demo cómico, el de los "Banqueteños"».

${ }^{27}$ A lo largo de este trabajo nos hemos guiado, generalmente, por la edición de Cassio 1977 [C]; sin embargo, hemos tenido presentes en el cotejo textual los trabajos de Kassel y Austin 1984 [K-A], Kock 1880 [K] y Edmonds 1957 [E]. Se aclarará en forma explícita cuando se trate de pasajes en que preferimos lectiones diferentes de las seleccionadas por el editor.

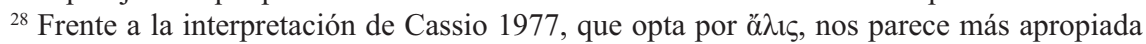
la expresión $\dot{\alpha} \lambda \lambda$ ' cĩ que conjeturan Kassel y Austin 1984 en su edición, puesto que decodifica los interlocutores; el adverbio, en cambio, no añade en este caso ningún valor esencial.
} 


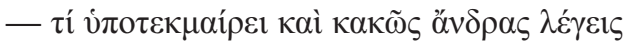

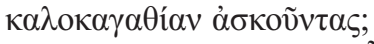

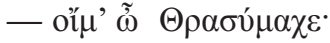

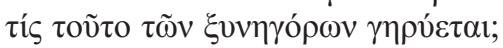

- Pero eres un ataúd, un ungüento, unas mortajas...

- Mira este «ataúd»; eso viene de Lisístrato.

- Igualmente estarás aterrorizado de nosotros con el tiempo.

- Ese «estarás aterrorizado» viene de los oradores.

- ¿A dónde te van a ir a parar estas palabras?

— De Alcibíades viene esto de «ir a parar».

- ¿Por qué supones y hablas mal de varones que practican la nobleza?

— ¡Ay, Trasímaco! ¿Cuál de los litigantes expresa esto? ${ }^{29}$

Se revela en el pasaje una contraposición de puntos de vista, referidos en esencia a la utilización de determinada terminología específica. La primera referencia a $\sigma о \rho \varepsilon ́ \lambda \lambda \eta$, neologismo que la única vez que se encuentra atestiguado - nuevamente en Aristófanes - constituye un apodo despectivo de un anciano ${ }^{30}$, es colocada en boca de uno de los hijos dentro de un cruce verbal que sostiene con su padre. Como se ve en el intercambio dialógico, este joven ha sido entrenado en los usos léxicos de los que su padre critica en forma reiterada al identificar — en intervenciones paralelas - ecos de un vocabulario propio de la oratoria: la interjección final trágica, ớ $\mu \alpha$, que frecuentemente constituye una señal de dolor, da la pauta más evidente acerca de la reacción paterna frente al nuevo discurso de su hijo.

Increpado por su padre a causa de la procedencia de expresiones como $\kappa \alpha \tau \alpha \pi \lambda \alpha \gamma \eta ́ \sigma \varepsilon є$ o $\dot{\alpha} \pi \circ \beta \eta ́ \sigma \varepsilon \tau \alpha$ — que para el oído del auditorio debían sonar

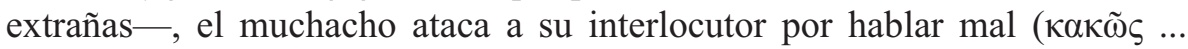
$\lambda \varepsilon ́ \gamma \varepsilon ı \zeta)$ de quienes practican la $\kappa \alpha \lambda о \kappa \alpha \gamma \alpha \theta i \alpha^{31}$. En este juego retórico, evidenciado en las palabras del joven, se torna patente la oposición sustancial entre

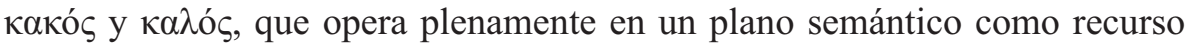
de argumentación.

${ }^{29}$ La traducción del texto griego en esta cita y en las siguientes es propia.

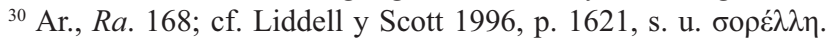

${ }^{31}$ Acerca de los alcances de este término, que por primera vez aparece testimoniado en este pasaje, ver el tradicional trabajo de Gomme 1953, pp. 65-68 y, especialmente, De Ste. Croix 1972, pp. 371-376. 
Varios puntos son interesantes en todo este fragmento: en primer lugar, la inversión de los argumentos, manifiesta en el hecho de que quien es «criticado» por actualizar un léxico ajeno termina acusando al «crítico» de una incorrecta utilización del discurso; en segundo lugar, la aparición de un término

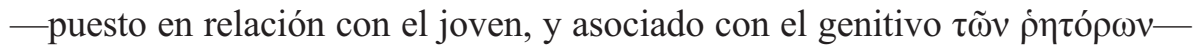
que recoge una semántica estrechamente ligada a la participación forense: $\tau \tilde{\omega} v$

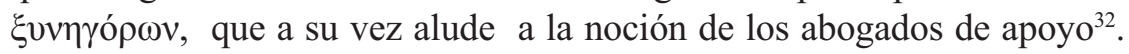

Los nombres propios, que constituyen una referencia habitual en Aristófanes como parte de sus invectivas personales, apuntan todos a figuras de gran peso político en la época. En efecto, Lisístrato era un orador frecuentemente criticado en la comedia por su presencia exagerada en el ágora, su frialdad y su miseria ${ }^{33}$, mientras que el joven Alcibíades comenzaba ya a mostrarse en los espacios públicos como un hábil orador ${ }^{34}$. En igual sentido, de modo paralelo, corresponde leer la mención de Trasímaco, por más que se trate en verdad de la única aparición del nombre en la comedia antigua ${ }^{35}$.

${ }^{32}$ Sobre esta figura esencial en el derecho ático, consultar Lavency 1964 y, más recientemente, el excelente trabajo de Rubinstein 2000. Como menciona Cassio 1977, p. 48, citando

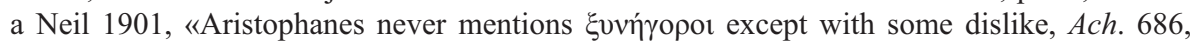
705; Nu. 1089; V. 482; fr. 362 [411 K.]».

${ }^{33}$ Kirchner 1901-1903, n. 9630. Cf. Ach. 854-5; V. 787-8, 1308-10; Eq. 1262. Según estos testimonios, tanto MacDowell 1971, p. 238, ad loc., como Sommerstein 1983, p. 206, ad loc. acuerdan que Lisístrato era conocido entre los atenienses por sus juegos verbales y su sarcasmo, como se advierte ya en nuestro pasaje.

${ }^{34}$ En esta época, Alcibíades debía contar apenas con poco más de unos veinte años (Kirchner 1901-1903, n. 600). Hacia el 422, en que se puso en escena Avispas, según MacDowell 1971, p. 133, ad loc., «... he was already familiar to the Athenian public as a speaker in the assembly and in the law courts»; cf. Sommerstein 1983, p. 156, ad loc. Las referencias a esta figura serán constantes en el corpus aristofánico, como indican las referencias de Ach. 716 y $V .44$, aunque no tan significativas como pretende justificar — con argumentos poco convincentes- Vickers 1997.

${ }^{35}$ En Holden 1902, p. 838 s. u., se comprueba que, en efecto, se trata de la única referencia en las comedias de Aristófanes (cf. también Todd 1962, 102, s. u.). Lo describe como nomen filii improbi et nouitiae disciplinae tabe infecti. Aparte de esta alusión, un Trasímaco es mencionado por Is. 4.2-6, 25, por Lys. 8.14-16 y aparece identificado en un fragmento

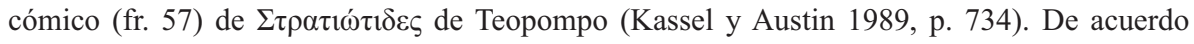
con Osborne y Byrne 1994, p. 229, las dos alusiones al nombre en la comedia apuntan a personajes ficticios. Creemos, no obstante, que su ubicación en este pasaje de Comensales, luego de la presencia de dos nombres claramente identificables para los espectadores de la pieza, justificaría pensar que se trataba también de un orador que formaba parte de la nueva generación de oradores sofistas. Dillon y Gergel 2003, pp. 203-216, dan por sentado que este 


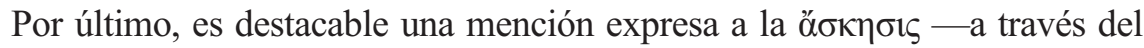

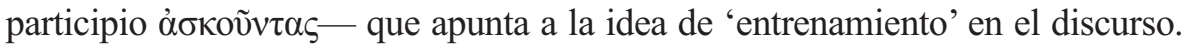

Relevados estos aspectos iniciales, corresponde pasar al siguiente fragmento, que todos los editores incluyen a continuación del primero:

Fr. 2 (199 K, 206 K-A)

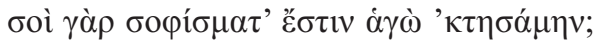

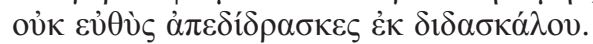

¿Pues son para ti sofismas las cosas que yo obtuve?

¿No te escapaste enseguida del maestro?

Se sigue aquí construyendo la antítesis: a través de los verbos «obtener» y «escaparse» nuevamente se consolidan en contraste la primera persona y la segunda respectivamente ${ }^{36}$. Las referencias a los $\sigma o \varphi i ́ \sigma \mu \alpha \tau \alpha$, al proceso de aprendizaje ( $\delta \delta \delta \dot{\sigma} \sigma \kappa \alpha \lambda \circ \varsigma$ ) y a un verbo $\kappa \tau \alpha \dot{o} \mu \alpha \alpha$, que se orienta hacia la adquisición económica, construyen un imaginario textual que, de modo indudable, apunta a la sofística. Los dos hermanos, pues, se consolidan textualmente y logran identificarse a partir de un contraste fundamental que, como línea divisoria, enfrenta por un lado la cultura tradicional y, por el otro, las enseñanzas modernas de los nuevos mercantes de la filosofía: uno se cultiva en este nuevo ambiente, el otro ha logrado escapar a tiempo ${ }^{37}$.

De hecho, los sofistas, surgidos en parte como una respuesta natural a la crisis política, proponían en su enseñanza la variabilidad de los valores y no-

nombre se corresponde con Trasímaco de Calcedonia. Contra, v. Storey 1988, para quien esta alusión apunta simplemente a una dramatis persona, sosteniendo que el conocido sofista solamente cobrará importancia en la década del 410.

${ }^{36}$ Se discute aquí, sin embargo, a quién se refiere la primera persona y a quién la segunda, es decir, quién menciona estas palabras. En nuestra opinión, se comprende mejor el pasaje si se atribuyen los versos al hijo disoluto: la segunda línea cobra más sentido como refuerzo de la primera (ya que da un sentido a la creencia de que el primer verso es una declaración verdadera) que como respuesta. El primer verso, por su parte, en que el hablante se enorgullece de sus habilidades o sophísmata, debe provenir del único personaje que efectivamente es un sofista.

${ }^{37}$ Esta lectura se enraíza, incluso, en la sintaxis de la oración. Bonnano 1984-1985, pp. 8889 , interpreta que «... la frase che contiene il $\gamma \alpha$ ó spiega il perché della sucesiva domanda: la "fuga da scuola", di cui il fratello "buono" dovrebbe dar conto a quello "cattivo", è motivata dalla convinzione, da parte del disertore, che gli insegnamenti dei $\delta\llcorner\delta \dot{\sigma} \sigma \kappa \alpha \lambda \circ \varsigma$ alla moda sono

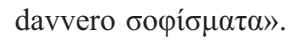


ciones, como modo de dar a aprender a sus «clientes» ${ }^{38}$ el don de la palabra, la posibilidad de defender con argumentos igualmente válidos posiciones contrarias $^{39}$, y la creación de lo verosímil a partir de un discurso persuasivo ${ }^{40}$. Así, la búsqueda de la verdad absoluta queda relegada por la victoria del relativismo: la convencionalidad de los valores permite su modificación y puesta en duda ${ }^{41}$. Es evidente, a partir del tono indignado que parece mostrar el hablante, que en nuestro pasaje advertimos ya un cierto uso peyorativo del término, que luego sin duda afianzará la interpretación platónica ${ }^{42}$. Aristófanes nos indica cómo ya en la época algunos contemporáneos parecían suponer que la sofística contribuyó activamente al progresivo deterioro espiritual de la $\pi$ ó $\lambda \varsigma^{43}$.

El joven educado en la ciudad, pues, ha sido entrenado por estos nuevos profesionales de la retórica. Según su padre, fue enviado a una escuela donde sólo aprendió a beber, a cantar malas tonadas, a cenar y festejar al estilo de Siracusa y Síbaris e - incluso- a pedir vino de Quíos en una jarra laconia:

\section{Fr. $21,216 \mathrm{~K}, 225 \mathrm{~K}-\mathrm{A}$}

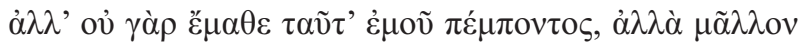

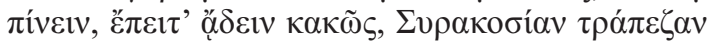

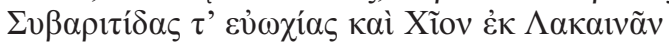

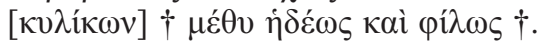

Pero no aprendió esto al enviarlo yo, sino más bien a beber, luego a cantar mal, a (disfrutar) una mesa siracusana, banquetes sibaritas y «Quío» de las lacedemonias, vino [de copa], de modo agradable y amistoso.

Pero la instrucción, al menos en cuanto a su estilo discursivo, parece haberlo convertido en un buen querellante pragmático. En un pasaje en el que seguramente describe lo que hacía durante sus experiencias de aprendi-

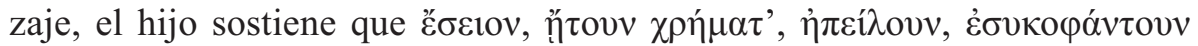
('sacudía, buscaba plata, amenazaba, delataba', fr. 24 C, 219 K, 228 K-A).

\footnotetext{
${ }^{38}$ En general, es sabido que estos sofistas cobraban a aquellos interesados en sus enseñanzas, de modo que sus alumnos solían provenir de las clases más acomodadas de la ciudad (Corbato 1958, pp. 18-24).

${ }^{39}$ Kerferd 1981, p. 84.

${ }^{40}$ Sobre la estrechísima relación entre sofística, argumentación y retórica, ver Harrison 1964.

${ }^{41}$ Cassertano 1991.

${ }^{42}$ Cf. Pl., Prt. 312a, por caso.

${ }^{43} \mathrm{Cf}$. Wallace 1998.
} 


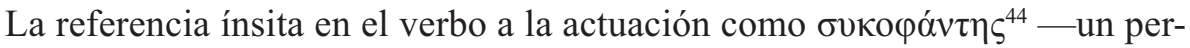
sonaje que será habitual en la escena aristofánica - da la pauta y decodifica los excesos del joven desde una perspectiva jurídica: aprendió a utilizar trampas verbales para obtener un enriquecimiento personal a expensas del aparato judicial ${ }^{45}$.

Conocemos ya la importancia de que estaba investido el lenguaje dentro de las discusiones filosóficas de la sofística ${ }^{46}$, y también la vinculación del $\lambda o ́ \gamma o \zeta$ con el éxito de una argumentación jurídica: basta para ello con recordar a Antifonte o el Encomio de Helena de Gorgias, emplazados en los orígenes de la oratoria como género ${ }^{47}$. En este sentido, la recurrencia del muchacho a una serie de términos específicos del universo de los tribunales suma entonces a las discusiones lingüísticas un nuevo plano, connotado por la identificación de un vocabulario propio de las cortes.

A pesar de la falta teórica de fiscales o expertos judiciales en Atenas, así como de la no profesionalización de los magistrados, no podemos negar la gran $\pi$ o $\lambda v \pi \rho \alpha \gamma \mu о \sigma u ́ v \eta$ que caracterizaba a los habitantes de la $\pi$ ó $\lambda \varsigma^{48}$. Tal como hemos adelantado, con la redacción y memorización de alegatos -instancias materializadas históricamente en el pasaje por escrito de las tramitaciones judiciales - ${ }^{49}$, surge en efecto el germen de la profesión de abogado — como ya sostenía Bonner 1927- y esto acarrea el surgimiento progresivo de un vocabulario semitécnico, que ya para fines del siglo $\mathrm{V}$ a. C. va apartando a aquellos que lo dominan en un círculo cada vez más exclusivo. En una celebración solemne como la que representa la puesta en acto del ejercicio judicial — tal como analizamos en la introducción — la lengua adquiere

\footnotetext{
${ }^{44}$ Acerca de las particularidades de estos litigantes aparentemente inescrupulosos, es sumamente ilustrativa la discusión entre la tradicional imagen negativa que ofrece Harvey 1990 y la visión positiva que le atribuye Osborne 1990 como figura reguladora de las injusticias sociales. Cf. Doganis 2001.

${ }^{45}$ MacDowell 1978, p. 62, manifiesta que «the kinds of case for which volunteers came forward more readily must have been those in which the prosecutor received a financial reward if he won the case»".

${ }^{46}$ El juego léxico, que tiene por base la noción del lenguaje como un sistema de signos meramente convencionales y arbitrarios, es un recurso privilegiado dentro de la sofística, tal como sostiene Dupréel 1948, p. 25.

${ }^{47}$ Cole 1991.

${ }^{48}$ Sobre la tranquilidad y el «activismo» en las ciudades de la antigüedad griega, especialmente en Atenas, cf. Demont 1990.

${ }^{49}$ Cf. Fezzi 2004, Faraguna 2007.
} 
un valor especial como instrumento para distinguir a los «iniciados» de los legos. Como sostiene Tambiah 1968, p. 179:

The role of language in ritual immediately confronts problems if placed in relation to a primary function of language which is that it is a vehicle of communication between persons. By definition, the persons in communication must understand one another. In ritual, language appears to be used in ways that violate the communication function.

Es lógico, pues, que el padre de $\Delta \alpha \imath \tau \alpha \lambda \tilde{\eta} \varsigma$ critique el manejo lingüístico forense de su hijo, que no llega a comprender ${ }^{50}$. Pero la situación se percibe como más grave cuando advierte que el muchacho entrenado, hábil para la retórica engañosa de los oradores, no está en condiciones de identificar siquiera las viejas expresiones homéricas que residen en la base de la cultura popular. El fragmento 28 [C] vuelve a cargar las tintas sobre el saber léxico:

\section{Fr. 28 (222 K, 233 K-A)}

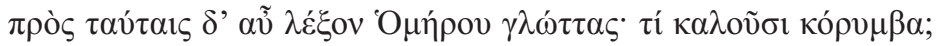

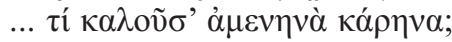

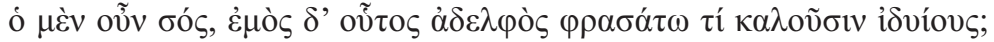

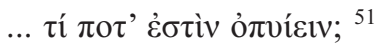

— Y además de éstas explica unas expresiones homéricas; ¿a qué llaman «cumbres»? ¿... a qué llaman «cabezas débiles»?

- Y que éste ahora, tu hijo y mi hermano, empiece a decir: ¿a qué llaman «testigos»? ¿... y qué es «dar en matrimonio»?

\footnotetext{
${ }^{50}$ «Here the poet's wit seizes on cultural and generational divides, much as the modern lawyer-basher may pose as a plainspoken lay person impatient with professional jargon» (Borowitz 2001, p. 248).

${ }^{51}$ A pesar de que los manuscritos (de Galeno, que es la fuente del pasaje con que contamos)

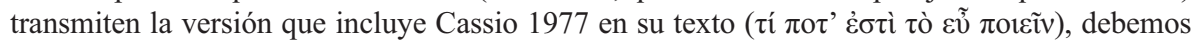
descartar la expresión por motivos métricos y de sentido. Nos satisface mucho más, en cambio,

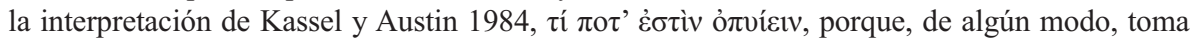
los aspectos ventajosos de las ediciones previas: la necesidad de la existencia de un término soloniano para que el pasaje cobre sentido (ỏ $\pi$ íciv, que resulta una conjetura de Dobree) y el respeto de lo que, en su primera parte, traen los testimonios ( $\tau^{\prime}$ $\left.\pi \mathrm{o} \tau^{\prime} \dot{\varepsilon} \sigma \tau i\right)$. Descartamos,

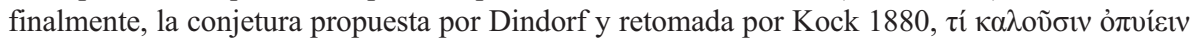
- en función del paralelismo con los versos anteriores-, pues carece de apoyo textual.
} 
Aquí, nuevamente, nos hallamos en presencia de otro pasaje del diálogo entre el padre y el hijo entrenado entre los sofistas. Cuando el padre le pregunta en tetrámetros anapésticos qué significa una serie de términos propios de Homero, el hijo se defiende dirigiéndose deícticamente hacia el otro hermano para que éste - en idénticos términos - identifique, por su parte, un

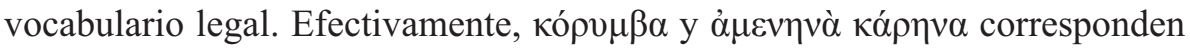
a expresiones épicas: la primera alude a la parte superior de los barcos ${ }^{52}$, mientras que la segunda, «cabezas débiles», se utilizaba como metonimia para indicar en Ilíada y Odisea a los muertos u hombres insensatos ${ }^{53}$.

Los términos invocados por el hijo, en cambio, remiten claramente a una jerga jurídica que se retrotrae incluso hasta el gran legislador Solón: ívíor apunta — desde su propia etimología $-{ }^{54}$ a la figura de los testigos oculares de un delito ${ }^{55}$; el infinitivo ó $\pi v i ́ \varepsilon v v$ aparece, en cambio, vinculado en su normativa con la institución del matrimonio ${ }^{56}$.

Todo esto, entonces, confluye en la contraposición entre la lengua poética de Homero y el lenguaje arcaizante del derecho ${ }^{57}$. Mientras que la epopeya proporciona en la cultura ateniense la base indiscutible de la $\pi \alpha 1 \delta \varepsilon i ́ \alpha$ social y el ámbito judicial se expande públicamente como un dominio abierto a to-

${ }^{52}$ Cf. Il. IX 241.

${ }^{53}$ Od. XVI 561, inter alia.

${ }^{54}$ Ferreira Leão 2001, p. 364.

${ }^{55}$ Cf. fr. 41b y 41c, siguiendo la numeración de la edición de Ruschenbusch 1966. En el segundo pasaje, según Eustacio (1158.19), Elio Dionisio sostenía que tanto Dracón como

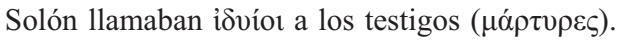

${ }^{56}$ Fr. 52a y 52b (Ruschenbusch 1966). Es interesante la propuesta de Bergk 1840 cuando -al sostener que etsi legebatur istis tabulis ... tamen et ab Homero est saepius usurpatum ut non potieit ignotum esse iuneni probe pudiceque educato- ofrece otra lectio para el pa-

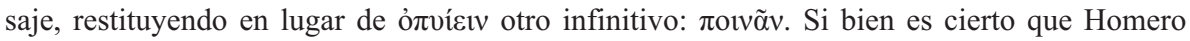

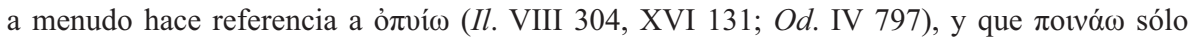
está testimoniado en una ley citada por D. 23.28 (donde significa 'reclamar una multa al culpable de homicidio'), no consideramos imprescindible esta propuesta, porque de hecho el primer término - a pesar de su aparición épica- preserva un sentido legal importante. Sin embargo, baste destacar - en cualquiera de ambos casos - la existencia de un vocabulario que claramente remite a la legislación soloniana.

${ }^{57}$ Ya Meineke 1840, p. 1033, reconocía que el muchacho entrenado en la ciudad satis uersatus fuit in iure y explica: multae autem uoces erant in Solonis legibus iam Aristophanis tempore plane obsoletae et prope emortuae, como muestra ya, por ejemplo, Lys. 10. Sobre este último discurso y la importancia de sostener una interpretación de la ley que no se restrinja literalmente a términos técnicos y formales sino a su intención en lenguaje vulgar, v. Hillgruber 1988, pp. 11-17. 
dos, sorprende en la discusión léxica la descontextualización del vocabulario. Sustentadas en la búsqueda de un efecto cómico, las palabras jurídicas utilizadas por el joven dan cuenta de una terminología técnica obsoleta, reservada exclusivamente para las leyes que se leían en los contextos judiciales. Fuera de ese ámbito, su uso se torna grotesco y desubicado.

Por lo demás, esta conducta nos permite presenciar, por segunda vez, las estrategias defensivas del hijo agraviado: dando vueltas al discurso, en este caso desplaza las preguntas de su padre hacia otros interrogantes dirigidos a su hermano, incorporándolo también al centro del $\dot{\alpha} \gamma \omega \dot{\omega} v^{58}$. Con ello, no sólo no responde ante el cuestionamiento: como un hábil profesional, desvía la atención haciendo del ataque su mejor defensa.

A través de sus palabras y sus acciones, se descubre que el joven fue educado en Atenas muy lejos de la tradicional educación griega y cerca del ejercicio contencioso. Un fragmento posterior incluye, brevemente, nuevas referencias al derecho:

Fr. $22(217 \mathrm{~K}, 226 \mathrm{~K}-\mathrm{A})$

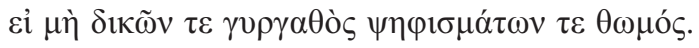

Si no (hubiese) una canasta de juicios privados, y un montón de decretos.

El término $\psi \eta ́ \varphi ı ø \mu \alpha$ traduce para el auditorio un valor jurídico indudable ${ }^{59}$; respecto del vocablo $\delta$ íkn, en cambio, aún se discute si en los primeros testimonios literarios presentaba ya un sentido moral o si en cambio se utilizaba exclusivamente para significar un arreglo de las controversias o un procedimiento de índole legal ${ }^{60}$, pero lo cierto es que en esta época — y sobre todo en plural— el término era utilizado ya para referirse al proceso legal en su conjunto ${ }^{61}$. Así,

\footnotetext{
${ }^{58}$ «It seems that a formal Agon on the merits of the two types of education was finally instituted, but it is uncertain whether this lay between the two brothers or the "improbus" and his father...» (Whittaker 1935, p. 186).

${ }^{59}$ Hansen 1978; Thomas 1996, p. 18. En este período, no puede reconocerse en principio ninguna diferencia semántica con el sustantivo vó $\mu$ os; sin embargo, debemos aclarar sobre este punto que en obras posteriores a la revolución del 411 a. C. pueden identificarse ya algunas divergencias importantes; la discusión sobre el pasaje de Ar., Th. 361-362, en este sentido, deviene significativo. Cf. Quass 1971.

${ }^{60}$ A favor de la primera de las posturas encontramos a Dickie 1978 quien se opone a la segunda de las opiniones — sostenida por Gagarin 1973-.

${ }^{61}$ Jones 1956, p. 26.
} 
con la evolución del sistema procesal ateniense también los procedimientos o recursos privados, incoados a instancia de parte interesada, pasaron a recibir esta denominación técnica como concepto opuesto a la acción que podía ser iniciada por cualquier ciudadano (llamada $\gamma \rho \alpha \varphi \eta)^{62}$ y en la cual quien no conseguía un quinto de los votos debía pagar una multa. El fr. 4, al hablar de $\tau$ ovं $\pi \dot{i} \pi \varepsilon \mu \pi \tau o v$, parece remitir a esta última característica de los litigios públicos ${ }^{63}$.

El tono irreverente del pasaje, finalmente, queda evidenciado en la generalización de los juicios, denotada por la existencia de dos sustantivos que apuntan con claridad a un colectivo indiscriminado.

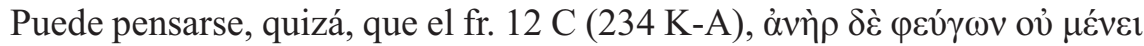
$\lambda u ́ \rho \alpha \varsigma \kappa \tau u ́ \pi o v$, esté también cimentado sobre criterios semejantes: siguiendo alguna posible línea de lectura, no sería necesariamente descabellado sugerir que la narración en tercera persona de un hombre que huye ( $\varphi \varepsilon v ́ \gamma \omega v)$ puede tener aquí el sentido de 'defenderse en juicio' ${ }^{64}$.

En todo caso, y más allá de esta última posibilidad, una pregunta parece desprenderse de lo analizado. En definitiva, ¿quieren decir estos pasajes que en $\Delta \alpha \iota \alpha \lambda \eta \tilde{\eta} \varsigma$ se representaba ante los espectadores una escena judicial —en una acción pública o privada-, como sucedería años después con el juicio casero de Filocleón en Avispas?

Los testimonios son escasos, pero en forma aislada encontramos algunos puntos interesantes que nos orientan hacia una posible respuesta. Entre los fragmentos, por ejemplo, se descubre una mención a la voluntad de llevar adelante una acusación por extranjería ante los jueces marítimos (vavto$\delta i ́ \kappa \alpha l)^{65} \mathrm{y}$, además, una alusión a un heliasta que «se arrastró a las puertitas

${ }^{62}$ Estos dos sentidos esenciales del término parecen coexistir en el mundo griego. Así,

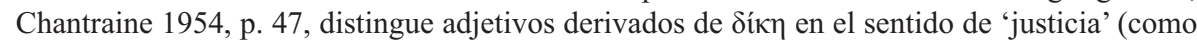
es el caso de $\delta$ íkalos) de otros que provienen de su valencia léxica en tanto «proceso judicial»»

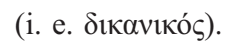

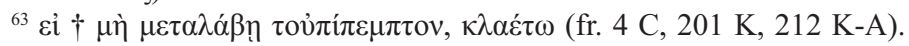

${ }^{64}$ Es posible pensar, por la estructura de la frase, que se trata de un proverbio y, por lo tanto, quien lo reproduce tiene la intención de que sea tomado en forma literal. No obstante, Cassio 1977, p. 58, ad loc., sugiere a partir de una comparacion con $V .1207$ que «si potrebbe pensare all'applicazione scherzosa di questo proverbio a uno che $\varphi \varepsilon v ́ \gamma \omega \mathrm{v}$ 'è accusato' in un processo».

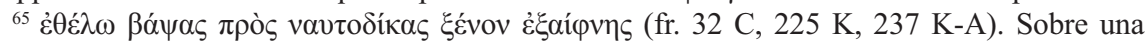
puesta a punto de las fuentes antiguas y las posiciones teóricas acerca de la naturaleza de estos magistrados - especialmente en lo que hace a sus discutidas funciones judiciales en el período clásico_, v. Cohen 1973, pp. 162-198. Gil 1989, pp. 75-76, interpreta este pasaje diciendo que el joven se muestra dispuesto a acudir a los nautódicas «para dejar en el acto convicto 
vaivén del juzgado» ${ }^{66}$, frase que reproduce una vez más sobre la escena un vocabulario técnico muy específico ${ }^{67}$. A partir de la lectura conjunta de ambos textos, la mención de dos tipos de magistrados distintos ${ }^{68}$, en pasajes que apuntan uno al futuro y el otro al pasado, nos permiten sólo concluir que las instancias forenses que se recrean textualmente son variadas y que seguramente, entonces, no apuntarían a una única actuación en juicio ${ }^{69}$.

Somos conscientes de que el estado fragmentario de la comedia no nos autoriza a avanzar mucho más allá en nuestras apreciaciones finales. Sin embargo, lo estudiado hasta aquí parece sentar bases suficientes para concluir con alguna afirmación de carácter más o menos global. De acuerdo a lo que puede leerse en los pasajes citados, llama poderosamente la atención en principio la abundancia de vocabulario jurídico en boca de diversos personajes de la obra ${ }^{70}$. Precisamente, la identificación de dichos lugares textuales contribuye a generar ciertas reflexiones respecto del modus operandi de la factura cómica. En efecto, hemos querido sugerir aquí que la riqueza discursiva de los pasajes parece fundar a menudo parte de su comicidad en la recurrencia a un vocabulario especializado que, frente al auditorio, se menciona fuera de su contexto natural de enunciación. Se trata de registros especializados utilizados en situaciones distintas de las de su normal invocación, lo cual genera risa por la sorpresa que despierta su carácter «desubicado».

a su progenitor de no reunir los requisitos de la ciudadanía». Es importante destacar que la tarea de estos oficiales se vinculaba con los asuntos de extranjería; esto reforzaría la posición de Fritzsche 1831, quien sostenía que el coro de la obra estaba integrado por comensales que asistían al templo de Heracles de Cinosarges, al que solían honrar los bastardos que no habían nacido de ambos padres atenienses (Ath. 234d). Puede inferirse que la contraposición entre ciudadanos y extranjeros (frecuente en la producción aristofánica posterior) ya encuentra su simiente en la obra.

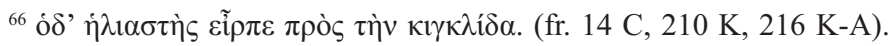

${ }^{67}$ Mediante la alusión a la $\kappa \nmid \gamma \kappa \lambda i \varsigma$, asistimos a la reproducción de un léxico judicial muy claro (Harp. s. u.), cf. Eq. 641; V. 124; Cassio 1977, p. 60.

${ }^{68}$ Cf. Bardelli 1972, pp. 234-245 y 274.

${ }^{69}$ En efecto, nada encontramos en los fragmentos que nos indique claramente la existencia de un juicio en escena, tal como por ejemplo hallamos en Avispas, no obstante lo cual, evidentemente, nada nos demuestra que no lo había.

${ }^{70} \mathrm{Sin}$ embargo, podemos conjeturar que dicha terminología forense es en gran medida mencionada tanto «por» el hijo disoluto, como «para» él o «respecto de» él. 


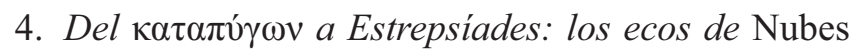

La relación de Comensales con la versión preservada de Nubes puede permitir reforzar estas afirmaciones y entender, desde otra óptica, el juego burlesco de la comedia pionera de Aristófanes. La parábasis del texto conservado de $N u b e s^{71}$, precisamente, apunta de modo directo e intratextual a la primera pieza, mencionando de hecho - en forma explícita- a sus dos personajes centrales. En efecto, el coro le da voz al autor para recordar de qué manera algunos hablaron muy bien, en su momento, del personaje prudente y del vicioso (ó $\sigma \omega ́ \varphi \rho \omega v \tau \varepsilon \chi \dot{\omega} \kappa \alpha \tau \alpha \pi \dot{\gamma} \gamma \omega v$, v. 529). Esta referencia, que puede dejar entrever alguna forma de patronazgo ${ }^{72}$ o de ayuda en la puesta en escena de su primera obra ${ }^{73}$, sirve para colocar a la pieza en términos de un hijo expuesto ( $\dot{\xi} \xi \dot{\xi} \theta \eta \kappa \alpha$, v. 531) y para posicionarse el mismo compositor como

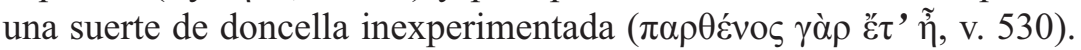

Alabando al público en una clara captatio beneuolentiae propia de la retórica que caracteriza toda la parábasis ${ }^{74}$, Aristófanes aprovecha el contrapunto brindado por la oposición $\sigma \omega ́ \varphi \rho \omega v / \kappa \alpha \tau \alpha \pi \dot{\gamma} \gamma \omega v$ para criticar a los comediógrafos contemporáneos (537-544) y alabar su propia productividad: haciendo uso de una lógica antitética, dice haber evitado engañar a la audiencia al rechazar la presentación de lo mismo dos o tres veces (ov̉ $\delta$ '

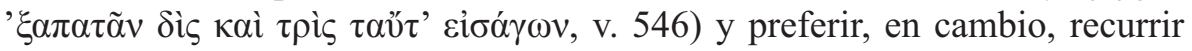

${ }^{71}$ Dover 1968, pp. lxxx-xcviii, da evidencias concretas para la existencia de dos versiones diferentes de la obra. Existen discusiones respecto de la fecha de producción de la segunda versión; mientras que un autor como Storey 1990, 1993, sostiene que debe fecharse alrededor del 418 (Dover 1972, p. 104, por ejemplo, coloca como fecha el 419/418; Henderson 1993, p. 600, concluye que ha debido ser terminada hacia el 418/417), Kopff 1990 recurre a evidencias externas para sugerir una postergación de su composición hasta el 414 o 413. Sommerstein 1991, p. 2, explica bien que la obra Baptai de Éupolis debe ser tomada como un terminus ante quem, de modo que la segunda puesta en escena de nuestra obra no puede ser posterior a la fecha estimada de 415: en función de referencias propias de la pieza, propone con criterio, entonces, una brecha temporal que va del 418 al 416. Acerca de las dos versiones de la comedia, pueden consultarse además Henderson 1993, Sommerstein 1997, Casanova 2000 y Revermann 2006, pp. 326-332.

${ }^{72}$ Halliwell 1980, pp. 42-43.

${ }^{73}$ Sommerstein 1991, p. 187, aclara que «... it makes sense if we suppose that in 428, before submitting his first play to the archon in the hope of being "given a chorus", Ar. showed the script to two or three men of social distinction and literary discernment, and that they were instrumental in persuading the archon to find a place in the festival programme for this very young dramatist».

${ }^{74}$ Rivers 1985, pp. 174-175. 
siempre a sus habilidades para introducir nuevas formas de comedia, distintas entre sí y cada una de ellas muy adiestrada (vv. 547-548):

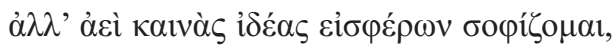

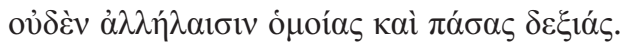

La importancia que el autor atribuye a su originalidad, marcada insistente-

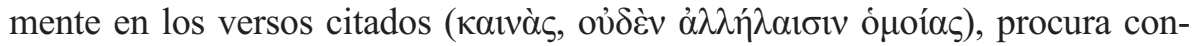
seguir una distancia entre sus propias estrategias de composición poética y

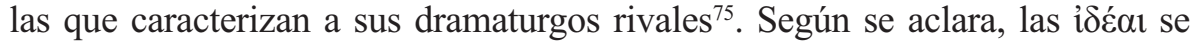
renuevan, utilizando dos términos que son fundamentales en el campo semántico que Aristófanes construye en torno de lo bueno y deseable ${ }^{76}$. Esta alusión - consideramos - es lo suficientemente clara como para poner en algún riesgo las posiciones que sostienen que el argumento de Nubes constituye una «copia» de la trama ya presentada en Comensales. En este sentido, por caso, dejamos asentada aquí nuestra opinión respecto de la necesidad de dejar de lado la hipó-

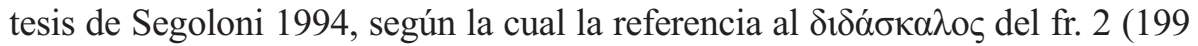
K, 206 K-A) apuntaría de modo directo al personaje de Sócrates.

Si lo que Aristófanes destaca es lo novedoso de sus propuestas ${ }^{77}$, parece difícil suponer la recurrencia a una imitación esquemática de la distribución de personajes o a un calco de la personalidad del protagonista dramático. Podría alegarse, sin embargo, que el autor se enorgullece de su originalidad en el mismo momento en que nos está presentando una segunda versión de Nubes y poco antes de poner en escena todos los clichés de la «baja» comedia que se ha encargado de criticar. No sin razón, ello bastaría para marcar hasta qué punto Aristófanes está en condiciones de proclamar, abiertamente a su

${ }^{75}$ En esta cita, Cavallero 2004 sostiene que la palabra clave es ảeì, entendiendo que lo que Aristófanes hace es señalar que él —como autor - siempre se ocupa de probar cosas nuevas. En otro trabajo nos hemos ocupado de estudiar cómo el comediógrafo se esfuerza en Caballeros por criticar la burda imitación, en ese caso de las habilidades litigiosas (Buis 2005).

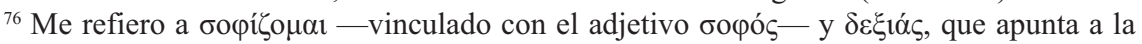
destreza del propio autor. Sobre la importancia de estos dos términos en la obra, ver Cavallero 2005-2006, pp. 83-88.

${ }^{77}$ En este mismo sentido, podemos recordar la idea contenida en los vv. 1052-1055 de Avispas, en los que se testimonia que los autores que buscan incluir novedades en sus obras deben

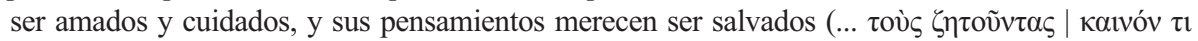

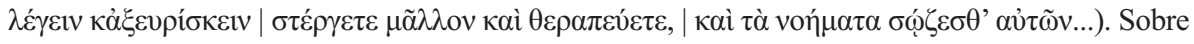
lo novedoso en Aristófanes como categoría fundamental de análisis, ver Fernández 2006. 
público, algo que en el fondo no duda en violar o incumplir. Esta incoherencia entre el decir y el hacer, que sin duda puede apreciarse en la comedia aristofánica, no alcanza para negar que el dramaturgo haya procurado generar una innovación en Nubes respecto de Comensales. Precisamente, un trabajo en torno a los paralelos entre las obras permite sostener que el patrón agencial no coincide en ambas comedias ${ }^{78}$.

En efecto, a diferencia de lo que ocurre con la caracterización de Fidípides, los fragmentos de Comensales presentan a dos hijos construidos desde una poética de los contrarios. Por lo demás, el viejo Estrepsíades de Nubes se comporta de un modo absolutamente distinto del rol de padre que reflejan los versos preservados de la primera obra. Así, en una suerte de inversión genera-

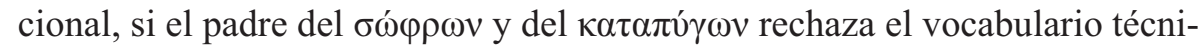
co de las cortes, Estrepsíades parece asemejarse mucho más en sus opiniones y criterios al papel del joven educado en la nueva sofística. Esto se advierte incluso en las propias palabras que el autor le atribuye: los ecos del fr. 1 se

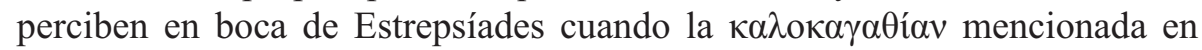
el pasaje es recordada y reproducida por el protagonista en $N u$. 101, como

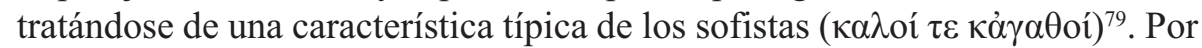
otra parte, debe decirse que hay también superposiciones interesantes entre el muchacho de Comensales y el Argumento Peor (quien también es calificado

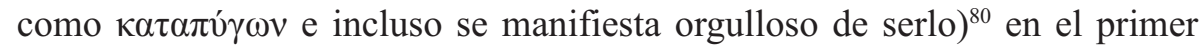
agón de Nubes, así como puntos de contacto con Fidípides en el segundo.

\footnotetext{
${ }^{78}$ Nos apartamos aquí de la mayor parte de los filólogos e historiadores, que ven una relación directa y una suerte de equivalencia entre ambas obras en términos de sus personajes. En la última década citemos, por ejemplo, a Segal 2001, p. 47, quien afirma que tanto Comensales como Nubes se fundan en la batalla de las generaciones y que, como consecuencia, tenemos en las dos piezas «the derision of a new man who can't learn new tricks». Esta proyección de lo que sabemos de Nubes a lo que desconocemos de Comensales es, en nuestra opinión, metodológicamente sospechosa.

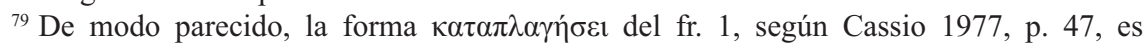
mencionada en el escolio a $N u$. 1174, donde se dice que Estrepsíades usa palabras como esa para «vincere con un comportamento sfacciato» a sus adversarios. Es llamativa también la reiteración de un vocabulario vinculado con la retórica: en el breve fr. 33 (226 K), $\tilde{\omega} \pi \alpha \rho \alpha$ -

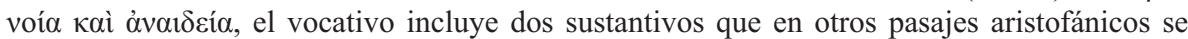
relacionan explícitamente con las enseñanzas sofísticas. De hecho, $\pi \alpha \rho \alpha v o i ́ \alpha$ es el nombre que utiliza Fidípides cuando amenaza iniciarle una acción pública ( $\gamma \rho \alpha \varphi \eta ́)$ a su padre en $N u$. 845,

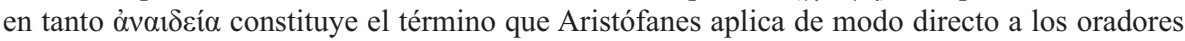

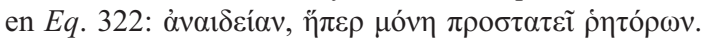

${ }^{80} N u$. 909, 1023; cf. Ludwig 2002, pp. 248-249.
} 
En otras palabras, se advierte con relativa claridad que las mismas expresiones que en $\Delta \alpha i \tau \alpha \lambda \tilde{\eta} \varsigma$ parecen atribuirse al joven educado en la ciudad - referidas no solamente a conocimientos científicos ${ }^{81}$ sino en esencia a estrategias de ejercicio retórico- terminan caracterizando en Nubes, por lo menos, a ambos personajes centrales (padre e hijo, progresivamente), configurando especialmente en Estrepsíades a un héroe cómico sui generis, inaudito para la comedia antigua ${ }^{82}$.

En síntesis, podemos afirmar que si, como sabemos, la lectura de los pasajes conservados de Babilonios resultan útiles para analizar las referencias intratextuales de Acarnienses y Caballeros $^{83}$, lo cierto es que parece extremadamente difícil encarar Comensales sin pensar en las alusiones contenidas en el texto de Nubes. Sin embargo, en esa interpretación cruzada consideramos que no puede observarse un paralelismo estructural ni una simetría compositiva, sino - en todo caso- un mismo interés subyacente por mostrar - a la luz del juego generacional- los peligros del avance de la sofística en el plano del ejercicio judicial ${ }^{84}$.

\section{Conclusiones}

La presencia de una terminología jurídica es permanente en los fragmentos trasmitidos de $\Delta \alpha \imath \tau \alpha \lambda \tilde{\eta} \varsigma$, y si bien en muchos casos se trata de pasajes breves e inconexos, al menos es posible echar luz sobre ciertos aspectos, luego de examinar su contenido, y sugerir algún comentario.

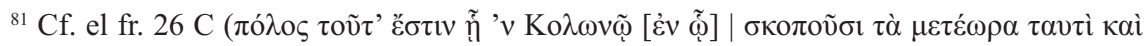
$\tau$ $\alpha ̀ ~ \pi \lambda \alpha ́ \gamma 1 \alpha \tau \alpha v \tau i ́)$, donde queda claro que también — dentro de las enseñanzas sofísticas - se incluyen la geometría y la astronomía (Bonnano 1984-1985, pp. 91-92).

${ }^{82}$ De hecho, es un protagonista sumamente extraño, dado que está condenado al fracaso y, además, lleva a cabo la escena más violenta de la comedia antigua conservada (el incendio final del Pensadero); cf. Fernández 2005-2006, p. 23, quien interpreta el final como una reconciliación de la pieza — y de su personaje central — con las expectativas de la audiencia. La crítica ha entendido estas particularidades únicas considerando que Nubes representa un híbrido que juega con la mezcla de tragedia y comedia. Cavallero 2006, por su parte, opina que con esta imbricación de géneros — calificada en el propio texto como trygoidia- Aristófanes demuestra el peso cívico-social de su propia composición poética.

${ }^{83}$ Esto lo hemos estudiado profundamente en Buis 2004b.

${ }^{84}$ En el caso de Nubes, hemos analizado la comedia y su relación con las discusiones contemporáneas en materia de interpretación judicial en Buis 2006. 
En principio, nadie negaría que la abundancia de lexemas legales es llamativa en la comedia; en los distintos versos, aparece una permanente reflexión respecto del conocimiento del vocabulario específico de la actividad de las cortes. El efecto de burla, precisamente, pareciera estar dado en estos fragmentos por la descontextualización de un vocabulario formulario y arcaico, propio de las antiguas leyes, que aparece citado fuera de los tribunales y en el marco de una conversación familiar ${ }^{85}$. Si mediante un espectáculo ritualizado - como sucede con la puesta en escena de un proceso judicialuna comunidad se identifica a través de una simbología común en espacios determinados ${ }^{86}$, la lengua utilizada en esos contextos solemnes restringe el saber al seno de una élite entrenada que inmediatamente se diferencia allí del ciudadano común ${ }^{87}$. La aparición del ritualismo en otros ámbitos implica su quiebra, y el uso de esta operación es intencionada en el autor: todo traslado espacial y contextual sitúa fuera de lugar, desplaza y vulgariza la formalidad de la ceremonia consagrada y, con ello, se transforma en un eficiente mecanismo de comicidad frente a los terceros.

El estudio lingüístico de las intervenciones de los personajes nos permitió poner en tela de juicio, desde el tejido dramático, la afirmación generalmente suscrita de que en la sociedad ática no encontramos una jerga forense ni la presencia de «expertos» de la actividad judicial de la pólis. Pero además, y por otra parte, visitar y estudiar estos fragmentos - sobre todo en el juego relacional que se establece con Nubes - revela interesantes aspectos acerca de las funciones que cumple el derecho ático en el seno de un género como la

\footnotetext{
${ }^{85}$ Komornicka 1967, p. 66, señala que uno de los recursos paródicos propios de Aristófanes consiste, precisamente, en descontextualizar el vocabulario legal: "C'est à ce domaine de parodie qu'appartiennent les scènes et les vers où Aristophane ridiculise la langue des harangues tenues devant le tribunal, à l'assemblée du peuple et au Conseil, ainsi que nombre de formules empruntés aux actes publics, aux lois d'État, bref tout un verbiage juridique». No es ni más ni menos que uno de los lenguajes técnicos cuyo vocabulario incorpora con efectos cómicos (Dover 1970, p. 8). La poca familiaridad que supone el sentido técnico de ciertas palabras constituye, según Denniston 1927, p. 113, un elemento preciado para las bromas del humorista.

${ }^{86}$ Como sostiene Harrison 1992, p. 225, «... communities and political interest groups define themselves by exclusive rituals and distinctive symbolisms».

${ }^{87}$ «It is perhaps relevant to note, whenever we meet such formalised oral or written texts, that their "archaicness" may also be related to the fact that they are composed in a special style, which uses highly symbolic devices, specially coined words, and words without meaning to fill in gaps» (Tambiah 1968, p. 182).
} 
comedia antigua. A partir de una riqueza expresiva y de una serie de resortes cómicos sustentados en una crítica de la sofística y de la profesionalización del manejo de causas judiciales, esta comedia debut se convierte, así, en un verdadero muestrario - el primero- de las grandes inquietudes y obsesiones que acompañarán al autor en su carrera literaria ${ }^{88}$.

\section{BiBLIOGRAFÍA}

Ediciones críticas, escolios, comentarios e instrumenta studiorum

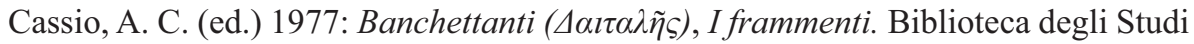
Classici e Orientali 8, Pisa.

Dover, K. J. (ed.) 1968: Aristophanes: Clouds, Oxford.

Dübner, F. (ed.) 1855: Scholia Graeca in Aristophanem cum prolegomenis grammaticorum, París.

Edmonds, J. M. (ed.) 1957: The Fragments of Attic Comedy after Meinecke, Bergk, and Kock. Augmented, newly edited with their Contexts, annotated and completely translated into English Verse, Leiden.

Fåhraeus, F. I. (ed.) 1886: De argumento atque consilio Daetalensium fabulae Aristophaneae commentatio academica, Upsala.

Fritzsche, F. V. (ed.) 1831: De Daetalensibus Aristophanis commentatio, Leipzig.

Hillgruber, M. (ed.) 1988: Die zehnte Rede des Lysias. Einleitung, Text und Kommentar mit einem Anhang über die Gesetzeinterpretationen bei den attischen Rednern, Berlín-Nueva York.

Holden, H. A. (ed.) 1902: Onomasticon aristophaneum sive index nominorum quae Aristophanem leguntur, Cambridge (reprod. reprogr. Hildesheim-Nueva York, 1970).

Holwerda, D. (ed.) 1977: Scholia vetera in «Nubes». Scholia in Aristophanem, Pars I, Fasc. III,1, Groninga.

Kassel, R. y Austin, C. (eds.) 1984: Poetae Comici Graeci. Vol. III, 2 Aristophanes, testimonia et fragmenta, Berlín-Nueva York.

- (eds.) 1989: Poetae Comici Graec. Vol. VII Menecrates - Xenophon, BerlínNueva York.

Kirchner, J. (ed.) 1901-1903: Prosopographia Attica, Berlín.

\footnotetext{
${ }^{88}$ Quisiera agradecer aquí los comentarios y sugerencias del Prof. Alan H. Sommerstein, que han sido extremadamente valiosos para mejorar algunos aspectos de este artículo. Por supuesto, no hace falta decir que las opiniones vertidas y los errores en que puedo haber incurrido en estas páginas son de mi exclusiva responsabilidad.
} 
Kock, T. (ed.) 1880: Comicorum Atticorum Fragmenta, Leipzig.

Liddell, H. G. y Scott, R. 1996: A Greek-English Lexicon. Revised and augmented throughout by H. S. Jones, with the assistance of Roderick McKenzie, with a revised supplement, Oxford.

MacDowell, D. M. (ed.) 1971: Aristophanes. Wasps, Oxford.

Meineke, A. (ed.) 1840: Fragmenta comicorum graecorum. Vol. II Fragmenta poetarum comoediae antiquae continens, Pars II, Berlín.

Neil, R. A. (ed.) 1901: The Knights of Aristophanes, Cambridge.

Osborne, M. J. y Byrne, S. G. 1994: «Attica», en Fraser, P. M. y Matthews, E. (eds.), A Lexicon of Greek Personal Names, vol. II, Oxford.

Roeter, F. E. (ed.) 1888: De Daetalensium fabula Aristophanis, Erlangen.

Ruschenbusch, E. (ed.) 1966: $\Sigma O 1 \Omega N \Omega \Sigma$ NOMOI, Wiesbaden.

Sommerstein, A. H. (ed.) 1980 (1992, 3. ${ }^{\mathrm{a}}$ ed.): The Comedies of Aristophanes. Vol. 1. Acharnians, Warminster.

- (ed.) 1981: The Comedies of Aristophanes. Vol. 2. Knights, Warminster.

- (ed.) 1982 (1991, 3. ${ }^{\mathrm{a}}$ ed.): The Comedies of Aristophanes. Vol. 3. Clouds, Warminster.

- (ed.) 1983: The Comedies of Aristophanes. Vol. 4. Wasps, Warminster.

Todd, O. J. 1962: Index aristophaneus, Hildesheim.

Van Leeuwen, J. F. (ed.) 1901: Aristophanis Acharnenses, cum prolegomenis et commentariis, Leiden.

\section{Bibliografía secundaria}

Bardelli, N. 1972: La giuridizione in Atene, studiata in rapporto allo spirito e all'evoluzione della costituzione politica. Studia Juridica LXIX, Roma.

Beta, S. 2004: Il linguaggio nelle commedie di Aristofane. Parola positiva e parola negativa nella commedia antica. Bollettino dei Classici, Supp. 21/22, Roma.

Bonnano, M. G. 1984-1985: «Note ai Banchettanti di Aristofane», MC 19-20, pp. 87-97.

Bonner, R. J. 1927: Lawyers and Litigants in Ancient Athens, Chicago.

Borowitz, A. 2001: «The Wasps and The Litigants: Courtroom Satires of Aristophanes and Racine», Legal Studies Forum 25, 3-4, pp. 247-262.

Brockmann, C. 2003: Aristophanes und die Freiheit der Komödie. Untersuchungen zu den frühen Stücken unter besonderer Berücksichtigung der Acharner, Berlín.

Bryant, A. A. 1907: «Boyhood and Youth in the Days of Aristophanes», HSCP 18, pp. 73-122.

Buis, E. J. 2004a: «How to Play Justice and Drama in Antiquity: Law and Theater in Athens as Performative Rituals», Florida Journal of International Law 16, pp. 697-725. 
Buis, E. J. 2004b: «Querellas públicas y defensas teatrales en Acarnienses: leyendo el enfrentamiento Cleón/Aristófanes desde los escolios», PhaoS 4, pp. 59-84.

- 2005: «Cómo plagiar la litigiosidad del enemigo y no reír en el intento: la estrategia desvergonzada de la mímesis jurídica como clave de lectura en Caballeros», Eirene. Studia graeca et latina 41, pp. 140-160.

- 2006: «Sofística, interpretación jurídica y comedia: la ley contra la $\Gamma O N E \Omega N$ $\mathrm{KAK} \Omega \Sigma \mathrm{I} \Sigma$ y la convencionalidad del derecho ateniense en Aristófanes», en Gastaldi, V. y Gambón, L. (coords.), Sofística y teatro griego. Retorica, Derecho y Sociedad, Bahía Blanca, pp. 103-136.

Cantarella, E. y Gagliardi, L. (eds.) 2007: Diritto e teatro in Grecia e a Roma, Milán.

Carey, C. 1994: «Legal Space in Classical Athens», $G \& R$ 41, 2, pp. 172-186.

- 2000: «Comic Law», Annali dell’ Università di Ferrara 1, pp. 65-86.

Casanova, A. 2000: «La revisione delle Nuvole di Aristofane», Prometheus 26, pp. 19-34.

Cassertano, G. 1971: Natura e istituzioni umane nelle dottrine dei sofisti, NápolesFlorencia.

Cavallero, P. A. 2004: «Aeí: una clave en la estética aristofánica», en Zecchin, G. y Napoli, J. (eds.), Ética y estética: de Grecia a la Modernidad, Universidad Nacional de La Plata, La Plata, CD-Rom.

- 2005-2006: «Algunas claves interpretativas de Nubes de Aristófanes», Circe, de clásicos y modernos 10, pp. 75-96.

— 2006: «Trygoidia: la concepción trágica de Nubes de Aristófanes», Emerita 74, 1, pp. 89-112.

Chantraine, P. 1954: «Grec $\triangle \mathrm{IKANIKO \Sigma »,} \mathrm{AFC} \mathrm{6,} \mathrm{pp.} \mathrm{45-56.}$

Cohen, E. E. 1973: Ancient Athenian Maritime Courts, Princeton.

Cole, T. 1991: The Origins of Rhetoric in Ancient Greece, Baltimore.

Corbato, C. 1958: Sofisti e politica ad Atene durante la Guerra del Peloponeso, Trieste.

De Ste. Croix, G. E. M. 1972: The Origins of the Peloponnesian War, Londres.

Demont, P. 1990: La cité grecque archaïque et classique et l'idéal de tranquillité, París.

- 1997: «Aristophane, le citoyen tranquille et les singeries», en Thiercy, P. y Menu, M. (eds.), Aristophane: la langue, la scène, la cité. Actes du colloque de Toulouse, 17-19 mars 1994, Bari, pp. 457-479.

Denniston, J. D. 1927: «Technical Terms in Aristophanes», $C Q$ 21, 3-4, pp. 113121.

Dickie, M. W. 1978: «Dike as a Moral Term in Homer and Hesiod», CPh 73, 2, pp. 91-101.

Dillon, J. y Gergel, T. 2003: The Greek Sophists, Londres. 
Doganis, C. K. 2001: «La sycophantie dans la démocratie athénienne d'après les comédies d'Aristophane», JS 2, pp. 225-248.

Dover, K. J. 1970: «Lo stile di Aristofane», QUCC 9, pp. 7-23.

- 1972: Aristophanic Comedy, Berkeley-Los Ángeles.

Dow, S. 1969: «Some Athenians in Aristophanes», AJA 73, pp. 234-235.

Dupréel, E. 1948: Les sophistes, Neuchâtel.

Easterling, P. 1999: «Actors and voices: reading between the lines in Aeschines and Demosthenes», en Goldhill, S. y Osborne, R. (eds.), Performance culture and Athenian democracy, Cambridge, pp. 154-166.

Faraguna, M. 2007: «Tra oralità e scrittura: diritto e forme della communicazione dai poemi omerici a Teofrasto», Etica \& Politica/Ethics \& Politics 9, 1, pp. 75-111.

Fernández, C. N. 2005-2006: «"El Pensadero era una fiesta” o cómo interpretar el final de Nubes», AFC 18-19, pp. 21-39.

- 2006: «"El día viejo y nuevo” (Nubes, v. 1134) o las novedosas ideas del conservador Aristófanes», Nova Tellus 24, 1, pp. 63-89.

Ferreira Leão, D. 2001: Sólon. Ética e Politica, Lisboa.

Fezzi, L. 2004: «Il passaggio da oralità a scrittura nel processo attico», LEC 72, pp. 109-118.

Foucart, P. 1873: Les associations religieuses chez les Grecs. Thiases, éranes, orgèons, París.

Gagarin, M. 1973: «Dike in the Works and Days», CPh 68, 2, pp. 81-94.

Garner, R. 1987: Law and Society in Classical Athens, Nueva York.

Gil, L. 1989: «El Aristófanes perdido», CFC 22, pp. 39-106.

Goldhill, S. 1989: «Reading Performance Criticism», G\&R 36, 2, pp. 172-182.

- 1999: «Programme Notes», en Goldhill, S. y Osborne, R. (eds.), Performance culture and Athenian democracy, Cambridge, pp. 1-29.

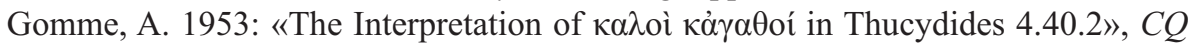
3, pp. 65-68.

Green, R. y Handley, E. 1995: Images of the Greek Theatre, Londres.

Hall, E. 1995: «Lawcourt Dramas: the Power of Performance in Greek Forensic Oratory», BICS 40, pp. 39-58.

Halliwell, S. 1980: «Aristophanes’ Apprenticeship», CQ 30, pp. 33-45.

Hansen, M. H. 1978: «Nomos and psephisma in Fourth-Century Athens», GRBS 19, pp. $315-330$.

Harrison, E. L. 1964: «Was Gorgias a Sophist?», Phoenix 18, pp. 183-192.

Harrison, S. 1992: «Ritual as Intellectual Property», Man (New Series) 27, 2 , pp. 225-244.

Harvey, D. 1990: «The sykophant and sykophancy: vexatious redefinition?», en Cartledge, P., Millett, P. y Todd, S. (eds.), Nomos. Essays in Athenian law, politics and society, Cambridge, pp. 103-121. 
Henderson, J. 1993: «Problems in Greek Literary History: The Case of Aristophanes' Clouds», en Rosen, R. M. y Farrell, J. (eds.), Nomodeiktes. Greek Studies in Honor of Martin Ostwald, Ann Arbor, pp. 591-601.

Jones, J. W. 1956: The Law and Legal Theory of the Greeks, Oxford.

Kavoulaki, A. 1999: «Processional performance and the democratic polis», en Goldhill, S. y Osborne, R. (eds.), Performance culture and Athenian democracy, Cambridge, pp. 292-320.

Kerferd, G. B. 1981: The Sophistic Movement, Cambridge.

Kloss, G. 2001: Erscheinungsformen komischen Sprechens bei Aristophanes. Untersuchungen zur antiken Literatur und Geschichte 59, Berlín-Nueva York.

Komornicka, A. M. 1967: «Quelques remarques sur la parodie dans les comédies d'Aristophane», QUCC 3, pp. 51-74.

Kopff, E. C. 1990: «The Date of Aristophanes' Nubes II», AJPh 111, 3, pp. 318-329.

Lavency, M. 1964: Aspects des la logographie judiciaire attique, París.

Lind, H. 1985: «Neues aus Kydathen. Beobachtungen zum Hintergrund der Daitales und der Ritter des Aristophanes», MH 17, pp. 249-261.

López Eire, A. 2003: «Lengua coloquial y "lenguas especiales" en la comedia aristofánica», en Il teatro e la città. Poetica e politica nel dramma attico del quinto secolo. Atti del Convegno Internazionale: Siracusa, 19-22 settembre 2001, Palermo, pp. 116-143.

Ludwig, P. W. 2002: Eros and Polis. Desire and Community in Greek Political Theory, Cambridge.

MacDowell, D. M. 1978: The Law in Classical Athens, Ithaca, 1986.

- 1995: Aristophanes and Athens. An Introduction to the Plays, Oxford.

Ober, J. y Strauss, B. 1990: «Drama, Political Rhetoric and the Discourse of Athenian Democracy», en Winkler, J. J. y Zeitlin, F. I. (eds.), Nothing to Do with Dionysos? Athenian Drama in its Social Context, Princeton, pp. 237-270.

Osborne, R. 1990: "Vexatious litigation in classical Athens: sykophancy and the sykophant», en Cartledge, P., Millett, P. y Todd, S. (eds.), Nomos. Essays in Athenian law, politics and society, Cambridge, pp. 83-102.

Quass, F. 1971: Nomos und Psephisma. Untersuchungen zum altgriechischen Staatsrecht. Zetemata 55, Múnich.

Revermann, M. 2006: Comic Business. Theatricality, Dramatic Technique, and Performance Contexts of Aristophanic Comedy, Oxford.

Rivers, J. E. 1985: «Rhetoric and Irony in Aristophanes' Clouds, 518-562», en Calder III, W. M., Goldsmith, U. K. y Kenevan, P. B. (eds.), Hypatia. Essays in Classics, Comparative Literature, and Philosophy Presented to Hazel E. Barnes on her Seventieth Birthday, Boulder, pp. 169-185.

Rubinstein, L. 2000: Litigation and Cooperation. Supporting Speakers in the Courts of Classical Athens. Historia Einzelschriften 147, Stuttgart.

Russo, C. F. 1994: Aristophanes. An Author for the Stage, Londres-Nueva York. 
Scafuro, A. 1997: The Forensic Stage: Settling Disputes in Graeco-Roman New Comedy, Cambridge.

Seaford, R. 1994: Reciprocity and Ritual. Homer and Tragedy in the Developing City-State, Oxford, 1999.

Segal, E. 2001: The Death of Comedy, Cambridge (MA).

Segoloni, L. M. 1994: Socrate a banchetto. Il Simposio di Platone e $i$ Banchettanti di Aristofane, Roma.

Sherberg, B. 1995: Das Vater-Sohn-Verhältnis in der griechischen und römischen Komödie, Tubinga.

Silk, M. S. 2000: Aristophanes and the Definition of Comedy, Oxford.

Sommerstein, A. H. 1997: «The Silence of Strepsiades and the Agon of the First Clouds», en Thiercy, P. y Menu, M. (eds.), Aristophane: la langue, la scène, la cité. Actes du colloque de Toulouse, 17-19 mars 1994, Bari, pp. 269-282.

- 2004: «Harrassing the Satirist: the Alleged Attempts to Prosecute Aristophanes», en Sluiter, I. y Rosen, R. M. (eds.), Free Speech in Classical Antiquity, Leiden, pp. 145-174.

Soulier, G. 1991: «Le théâtre et le procès», Droit et société. Revue internationale de théorie du droit et de sociologie juridique 17-18, pp. 9-24.

Storey, I. C. 1988: «Thrasymachos at Athens. Aristophanes fr. 205 (Daitales)», Phoenix 42, pp. 212-218.

- 1990: «Dating and Re-Dating Eupolis», Phoenix 44, pp. 1-30.

- 1993: «The Dates of Aristophanes' Nubes II and Eupolis' Baptai: A Reply to E. C. Kopff», AJPh 114, 1, pp. 71-84.

Strauss, B. S. 1993: Fathers and Sons in Athens. Ideology and Society in the Era of the Peloponnesian War, Londres.

Tambiah, S. J. 1968: «The Magical Power of Words», Man (New Series) 3, 2, pp. 175-208.

Thomas, R. 1996: «Written in Stone? Liberty, Equality, Orality and the Codification of Law», en Foxhall, L. y Lewis, A. D. E. (eds.), Greek Law in its Political Setting. Justifications not Justice, Oxford, pp. 9-31.

Todd, S. C. 1993: The Shape of Athenian Law, Oxford, 1995.

- 2005: «Law, Theatre, Rhetoric and Democracy in Classical Athens», European Review of History 12, 1, pp. 63-79.

Vickers, M. 1997: Pericles on Stage: Political Comedy in Aristophanes'Early Plays, Austin.

Wallace, R. W. 1997: «Poet, Public, and 'Theatrocracy': Audience Performance in Classical Athens», en Edmunds, L. y Wallace, R. W. (eds.), Poet, Public, and Performance in Ancient Greece, Baltimore-Londres, pp. 97-111.

Wallace, R. W. 1998: «The Sophists in Athens», en Boedecker, D. y Raaflaub, K. A. (eds.), Democracy, Empire, and the Arts in Fifth-Century Athens, Cambridge (MA), 127-155. 
Wallace, R. W. 2005: «Law, Attic Comedy, and the Regulation of Comic Speech», en Gagarin, M. y Cohen, D. (eds.), The Cambridge Companion to Ancient Greek Law, Cambridge, pp. 357-373.

Welsh, D. 1983: «IG $\mathrm{II}^{2}$ 2324, Philonides and Aristophanes' Banqueters», CQ 33, pp. 51-55.

Whittaker, M. 1935: «The Comic Fragments in Their Relation to the Structure of Old Attic Comedy», CQ 29, pp. 181-191.

Wiles, D. 1987: «Reading Greek Performance», $G \& R$ 34, 2, pp. 136-151.

- 2000: Greek Theater Performance: An Introduction, Cambridge.

Willi, A. 2003: The Languages of Aristophanes. Aspects of Linguistic Variation in Classical Attic Greek, Oxford.

Worthington, I. 2004: «Oral Performance in the Athenian Assembly and the Demosthenic Prooemia», en Mackie, C. J. (ed.), Oral Performance and Its Context. Orality and Literacy in Ancient Greece 5, Leiden-Boston, pp. 129-143.

Fecha de recepción de la primera versión del artículo: 14/02/2008

Fecha de aceptación del artículo: 13/06/2008

Fecha de recepción de la versión definitiva del artículo: 08/04/2009 